\title{
Unit Leadership and Climates for Evidence-Based Practice Implementation in Acute Care: A Cross-Sectional Descriptive Study
}

\author{
Clayton J. Shuman, PhD, RN ${ }^{1}$ (D) , Katherine Powers, RN, BSN², Jane Banaszak-Holl, $\mathrm{PhD}^{3}, \&$ \\ Marita G. Titler, PhD, RN, FAAN ${ }^{4}$ \\ 1 Rho, Assistant Professor, University of Michigan School of Nursing, Ann Arbor, MI, USA \\ 2 Rho, Research Assistant and DNP Student, University of Michigan School of Nursing, Ann Arbor, MI, USA \\ 3 Professor, Monash University, School of Public Health and Preventive Medicine, Melbourne, Australia \\ 4 Rho, Professor, University of Michigan School of Nursing, Ann Arbor, MI, USA
}

\author{
Key words \\ Evidence-based practice, implementation, \\ nurse manager, organizational climate

\section{Correspondence} \\ Dr. Clayton J. Shuman, 400 N. Ingalls, Ste. \\ 4162, Ann Arbor, MI 48109. \\ E-mail: clayshu@umich.edu
}

Accepted August 14, 2018

doi:10.1111/jnu.12452

\begin{abstract}
Purpose: The purposes of this study were to (a) describe nurse manager (NM) leadership behaviors for evidence-based practice, NM evidence-based practice competencies, and unit climates for evidence-based practice implementation in acute care, and (b) test for differences in NMs' and staff nurses' (RNs') perceptions.

Design: A multisite cross-sectional design was used to collect data from a sample of $24 \mathrm{NMs}$ and $553 \mathrm{RNs}$ from 24 adult medical-surgical units in seven U.S. community hospitals.

Methods: Responses were collected using electronic questionnaires, inclusive of the Nurse Manager Evidence-Based Practice Competency Scale (NM only), Implementation Leadership Scale, and Implementation Climate Scale. E-mail reminders and gift card lottery drawings encouraged response. Descriptive statistics described total and subscale scores by role. Differences in perceptions were evaluated using independent t-tests with Bonferroni correction $(\alpha=.05)$.
\end{abstract}

Findings: 23 NMs and 287 RNs responded $(95.8 \%$ and $51.9 \%$ response rates, respectively). NMs reported they were "somewhat competent" in evidence-based practice ( $M=1.62[S D=0.5] ; 0-3$ scale). NMs and RNs perceived leadership behaviors (NM: $M=2.73$ [SD =0.46]; RN: $M=2.88$ $[S D=0.78] ; 0-4$ scale) and unit climates for evidence-based practice implementation (NM: $M=2.16$ [SD = 0.67]; RN: $M=2.24$ [SD = 0.74]; $0-4$ scale) as evident to a "moderate extent." RN and NM perceptions differed significantly on the Proactive $(p=.01)$ and Knowledgeable $(p<.001)$ leadership subscales.

Conclusions: Evidence-based practice competencies and leadership behaviors of NMs, and unit climates for evidence-based practice were modest at best and interventions are needed. To close the research to practice gap, future studies should investigate the interplay between social dynamic context factors and implementation strategies to promote uptake of evidencebased practices.

Clinical Relevance: Critical attention is needed to build organizational capacity for evidence-based practices through development of unit leadership and climate for evidence-based practice to accelerate routine use of evidence-based practices for improving care delivery and patient outcomes. The three instruments described herein provide a foundation for nurse leaders to assess these dynamic context factors and design interventions or programs where there is opportunity for improvement. 
Context factors greatly influence the implementation and use of evidence-based practices (EBPs) and may help to explain why implementation strategies work in some settings but not in others (May, Johnson, Finch, 2016; Titler, 2010). Broadly defined, context is the setting or environment in which implementation takes place and includes structural and social dynamic factors. Structural factors are physical or operational characteristics of the setting that enable or constrain implementation of EBP (e.g., staffing, unit size, types of patients; Damschroder et al., 2009). Social dynamic factors pertain to the roles, relationships, and dynamics of the individuals and groups within a practice setting and include unit leadership and climate (Damschroder et al., 2009; Kitson \& Harvey, 2016). Although studies have identified structural factors that influence EBP in nursing units, very few studies have described social dynamic factors of unit leadership and climate for EBP implementation.

Nurse managers are optimally positioned to influence implementation of EBPs (Birken et al., 2016; Gifford, Davies, Edwards, Griffin, \& Lebanon, 2007; Sandström, Borglin, Nilsson, \& Willman, 2011). Competencies in EBP (Shuman, Ploutz-Snyder, \& Titler, 2018) and leadership behaviors supportive of EBP implementation (Aarons, Ehrhart, \& Farahnak, 2014; Shuman, Liu, et al., 2018) may contribute to facilitating unit climates more favorable for EBP implementation, and ultimately to patient receipt of evidence-based care. However, the EBP competencies and leadership behaviors of nurse managers in acute care settings have not been well described.

Unit climate for EBP implementation is facilitated by the practices, policies, and procedures managers expect, support, and reward (Ehrhart, Aarons, \& Farahnak, 2014; Schneider, Ehrhart, \& Macey, 2013). Although many implementation frameworks include culture as an important component in implementation, climate is often overlooked. Schein (2017) defines organizational culture as a pattern of shared basic assumptions that an organization learns while solving problems and are taught to newcomers. Organizational climate refers to the "shared meaning organizational members attach to the events, policies, practices, and procedures they experience and the behaviors they see rewarded, supported, and expected" (Ehrhart, Schneider, \& Macey, 2014, p. 2). Other studies have examined climates with a specified focus, such as safety climate and service climate (Ehrhart, Schneider, \& Macey, 2014); however, very few studies have investigated implementation-focused climates, and no study has described these climates in acute care nursing units.

\section{Conceptual Framework}

The Promoting Action on Research Implementation in Health Services (PARIHS) framework informed the conceptual model developed for this study (Figure S1). The PARIHS model contends that evidence, facilitation, and context are key determinants of successful EBP implementation (Kitson, Harvey, \& McCormack, 1998; Kitson et al., 2008). In the PARIHS framework, context includes leadership and climate, each bearing significant influence on implementation.

Social dynamic factors, which are of interest to this study, include nurse manager EBP competency, nurse manager EBP leadership behaviors, and unit climate for EBP implementation. Nurse manager EBP competency is defined as a nurse manager's self-perceived performance regarding the integration of knowledge, skills, abilities, and judgment about EBP (Shuman, PloutzSnyder, et al., 2018). Nurse manager leadership behaviors for EBP implementation are activities and behaviors used by nurse managers to facilitate EBP implementation efforts and create EBP climates on their units (Aarons, Ehrhart, \& Farahnak, 2014; Shuman, Liu, et al., 2018). Unit climate for EBP implementation is defined as nursing staff's perceptions of the practices, policies, and procedures that are expected, rewarded, supported, and resourced regarding EBP use and implementation in the unit (Ehrhart, Aarons, \& Farahnak, 2014).

Further understanding of leadership and climate for EBP implementation in acute care settings is needed and crucial for identifying and developing implementation strategies that address these factors. Therefore, the purposes of this article were to:

- Describe nurse managers' self-perceptions of their EBP competencies in hospital settings.

- Describe nurse managers' EBP leadership behaviors in hospital settings as (a) self-perceived and (b) as perceived by staff nurses.

- Describe (a) staff nurses' and (b) nurse managers' perceptions of unit climates for EBP implementation in hospital settings.

- Test for differences among staff nurse and manager perceptions of EBP implementation leadership behaviors and unit climates for EBP implementation.

\section{Methods}

\section{Design}

A multisite cross-sectional design was used to address the aims. The study was part of a larger 
study conducted in 2016-2017 (Shuman, 2017; Shuman, Liu, et al., 2018). Approvals from the ethics review board at the University of Michigan and at each participating hospital were obtained prior to data collection.

\section{Setting}

A convenience sample of seven community hospitals across the midwestern and northeastern United States were recruited through the National Nursing Practice Network. Twenty-four nursing units met the following inclusion criteria: (a) cared for adult patients ( $\geq 21$ years of age); (b) were designated as a medical, surgical, medical-surgical, or specialty unit (e.g., oncology, orthopedics, cardiac step-down unit); and (c) had an eligible nurse manager (described in the ensuing section). Mother-baby, pediatric, neonatal, psychiatric, and critical or intensive care units were excluded. For managers who supervised multiple eligible units, one of their units was randomly selected.

\section{Sample}

\section{Nurse managers}

Nurse managers were defined as registered nurses who oversaw unit-level operations and were responsible for patient care delivered by clinical staff. Inclusion criteria for nurse managers were: (a) licensed as a registered nurse; (b) had responsibility and accountability for unit-level operations; (c) was not serving in an interim role; and (d) was direct supervisor of nursing staff on the study unit. Senior nurse leaders holding executive positions that involved organizational and operational activities were excluded (such roles included chief nursing officer or department director). Twentyfour nurse managers were invited to participate.

\section{Staff nurses}

Staff nurses were licensed registered nurses who provided direct patient care on a study unit. Inclusion criteria for staff nurses were: (a) licensed as a registered nurse, (b) worked $\geq 0.40$ full-time equivalents (FTE), (c) provided direct patient care, and (d) designated as staff on the study unit. Those designated as contingency or agency staff or floated among units were excluded. Thirty eligible staff nurses from each study unit were randomly selected to receive email invitations to participate. For study units with fewer than 30 eligible staff nurses, all eligible nurses were sent invitations. The total of 553 staff nurses were invited.

\section{Study Variables and Measures}

\section{Nurse manager EBP competency}

Nurse manager EBP competency was measured using the 16-item Nurse Manager EBP Competency Scale (NM-EBPC), which measures competency in two domains: (a) EBP Knowledge and (b) EBP Activity (Shuman, Ploutz-Snyder, et al., 2018). EBP knowledge refers to what nurse managers know about EBP, while EBP activity refers to what they do in relation to EBP. Nurse managers indicate their self-perceived level of competency for each item using a Likert scale from 0 to $3(0=$ not competent; 1 = somewhat competent; 2 = fully competent; and 3 = expertly competent). The NM-EBPC total score is calculated by summing scores on each item and dividing by 16. Subscale scores are calculated by summing scores of items within a respective subscale and dividing by the total number of subscale items. The NM-EBPC scale has previously demonstrated content validity and internal consistency reliability (Cronbach's $\alpha=.95$ [total scale]; .90-.94 [subscales]; Shuman, Ploutz-Snyder, et al., 2018). Scale reliability for this study is described below.

\section{Nurse manager leadership behaviors for EBP implementation}

Leadership behaviors were measured using the 12item Implementation Leadership Scale (ILS), including both nurse managers' self-perceptions, and staff nurses' perceptions of their nurse manager, regarding leadership behaviors for EBP implementation in four domains: (a) proactive leadership, (b) knowledgeable leadership, (c) supportive leadership, and (d) perseverant leadership (Aarons, Ehrhart, \& Farahnak, 2014). Respondents indicate their level of agreement with each item using a Likert scale from 0 to $4(0=$ not at all; $4=$ very great extent). Total score is calculated by summing scores for each of the 12 items and dividing by 12 . Subscale scores are determined by adding the response values for each item within a subscale and dividing by the number of subscale items. In mental health settings, the ILS has demonstrated convergent $(r=0.62-0.75)$ and discriminant $(r=0.050-0.406)$ validity, as well as reliability (Cronbach's $\alpha=.98$ [total scale]; .95-.96 [subscales]); Aarons, Ehrhart, \& Farahnak, 2014). Reliability for the present study is described in the results below.

\section{Unit climate for EBP implementation}

Unit climate was measured using the 18-item Implementation Climate Scale (ICS), which measures the extent to which employees perceive their unit 
Table 1. Hospital and Unit Characteristics

\begin{tabular}{|c|c|c|c|c|}
\hline Hospital characteristics $(N=7)$ & M & $S D$ & $n$ & $\%$ \\
\hline \multicolumn{5}{|l|}{ Hospital size } \\
\hline Small (<100 beds) & & & 3 & 42.8 \\
\hline Medium (100-300 beds) & & & 2 & 28.6 \\
\hline Large (>300 beds) & & & 2 & 28.6 \\
\hline \multicolumn{5}{|l|}{ Hospital type (can be 1 or more) } \\
\hline Private/not for profit & & & 6 & 85.7 \\
\hline Private/for profit & & & 1 & 14.3 \\
\hline Church affiliated & & & 4 & 57.1 \\
\hline Urban & & & 3 & 42.8 \\
\hline Rural & & & 4 & 57.1 \\
\hline \multicolumn{5}{|l|}{ Magnet designation } \\
\hline Current & & & 2 & 28.6 \\
\hline Expired/no designation & & & 5 & 71.4 \\
\hline Average daily hospital censusa & 132.49 & 138.44 & & \\
\hline Average case mix index $x^{a}$ & 1.41 & 0.40 & & \\
\hline Unit characteristics $(N=24)$ & N & SD & $n$ & $\%$ \\
\hline Unit bed capacity & 24.99 & 9.52 & & \\
\hline Average daily unit census ${ }^{b}$ & 17.73 & 9.54 & & \\
\hline Average patient age ${ }^{b}$ & 63.99 & 5.24 & & \\
\hline Average skill mix (\% RN to other) & 60.00 & 10.00 & & \\
\hline Average RN HPPD ${ }^{b}$ & 7.31 & 1.49 & & \\
\hline \multicolumn{5}{|l|}{ Clinical nurse specialist } \\
\hline None (O hr) & & & 9 & 37.5 \\
\hline Part time (1-39 hr) & & & 10 & 41.7 \\
\hline Full time (40 hr) & & & 5 & 20.8 \\
\hline
\end{tabular}

Note. HPPD = hours per patient day; $\mathrm{RN}=$ registered nurse.

a Data collected over 6 months.

bData collected over 3 months.

to support EBP implementation in six domains: (a) the unit's focus on EBP, (b) educational support available for EBP, (c) recognizing staff for using EBP, (d) rewarding staff for using EBP, (e) hiring staff who value or use EBP, and (f) hiring staff open to innovation (Ehrhart, Aarons, \& Farahnak, 2014). Respondents select their level of agreement with each item using a Likert scale from 0 to $4(0=$ not at all; $4=$ very great extent). The ICS total score is calculated for each participant by summing scores across items and dividing by 18. Subscale scores are calculated by adding response values for subscale items then dividing by the number of subscale items. The ICS has demonstrated construct validity and reliability (Cronbach's $\alpha=.91$ [total scale]; .81-.91 [subscales]); Ehrhart, Aarons, \& Farahnak, 2014). Reliability for this study is reported in the results.

\section{Demographic data of participants}

Demographic data were collected, including age, sex, race, shift, education level, years of experience as a registered nurse, years of experience as a nurse manager, and years of experience as a registered nurse or nurse manager in the current hospital and unit.

\section{Hospital and unit characteristics}

The following data were collected to describe the hospitals: size, ownership type, location, Magnet ${ }^{\circledR}$ designation, average daily hospital census, and average case mix index. Unit-level characteristics included 3-month averages of unit bed capacity, daily unit census, patient age, skill mix (\% registered nurse to other), registered nurse hours per patient day, and clinical nurse specialist hours per week.

\section{Study Procedures and Data Collection}

Data collection was facilitated by site coordinators who were trained in data collection methods using a data collection manual tailored to each study site. Site coordinators helped to identify eligible study units, nurse managers, and staff nurses for random selection, and 
Table 2. Respondent Demographics by Role

\begin{tabular}{|c|c|c|c|c|c|c|c|c|}
\hline & \multicolumn{4}{|c|}{ Nurse manager $(n=23)$} & \multicolumn{4}{|c|}{ Staff nurse $(n=287)$} \\
\hline & M & $S D$ & $n$ & $\%$ & M & $S D$ & $n$ & $\%$ \\
\hline \multicolumn{9}{|l|}{$\overline{S e x}$} \\
\hline Female & & & 20 & 87.0 & & & 241 & 84.0 \\
\hline Male & & & 2 & 8.7 & & & 13 & 4.5 \\
\hline Missing & & & 1 & 4.3 & & & 33 & 11.5 \\
\hline \multicolumn{9}{|l|}{ Race } \\
\hline Caucasian & & & 19 & 82.6 & & & 240 & 83.6 \\
\hline Other & & & 2 & 8.6 & & & 16 & 5.4 \\
\hline Missing & & & 2 & 12.9 & & & 31 & 11.0 \\
\hline \multicolumn{9}{|l|}{ Education } \\
\hline Diploma & & & & & & & 7 & 2.4 \\
\hline Associate's & & & 3 & 13 & & & 83 & 28.9 \\
\hline Bachelor's & & & 12 & 52.2 & & & 170 & 59.2 \\
\hline Master's & & & 7 & 30.4 & & & 7 & 2.4 \\
\hline Missing & & & 1 & 8.6 & & & 20 & 7.0 \\
\hline \multicolumn{9}{|l|}{ Shift } \\
\hline Days & & & & & & & 102 & 35.6 \\
\hline Evenings & & & & & & & 13 & 4.5 \\
\hline Nights & & & & & & & 70 & 24.4 \\
\hline Rotate & & & & & & & 83 & 28.9 \\
\hline Missing & & & & & & & 19 & 6.6 \\
\hline Age (years) & 41.76 & 6.67 & & & 34.9 & 11.94 & & \\
\hline Years as RN & 15.64 & 6.06 & & & 7.84 & 9.88 & & \\
\hline Years as NM & 3.91 & 2.56 & & & & & & \\
\hline $\begin{array}{c}\text { Years in role } \\
\text { in current } \\
\text { hospital }\end{array}$ & 3.95 & 2.61 & & & 5.58 & 7.90 & & \\
\hline $\begin{array}{l}\text { Years in role } \\
\text { in current } \\
\text { unit }\end{array}$ & 3.05 & 2.46 & & & 4.89 & 7.23 & & \\
\hline
\end{tabular}

Note. $\mathrm{NM}=$ nurse manager; $\mathrm{RN}$ = registered nurse.

assisted with questionnaire distribution. Survey data were collected from nurse managers and staff nurses using electronic surveys via Qualtrics ${ }^{\circledast}$ (Qualtrics Software, 2015). Nurse managers and randomly selected staff nurses were sent an email inviting them to complete a questionnaire inclusive of the NM-EBPC (nurse manager only), ILS, ICS, and demographic items. Email reminders and a lottery drawing for a $\$ 100$ cash card encouraged response. We describe study procedures and data collection methods in more detail elsewhere (Shuman, 2017; Shuman, Liu, et al., 2018; see also Figure S2).

\section{Statistical Analysis}

Data were analyzed in $\mathrm{R}$ version 3.1.2 (R Core Team, 2016). Missing values were explored to identify patterns. If respondents completed less than $50 \%$ of a scale (NMEBPC, ILS, or ILS), their responses for that scale were not used. Scale reliability among nurse managers' and staff nurses' responses was evaluated using Cronbach's a. Descriptive statistics (mean and standard deviation) were calculated for each item, subscale, and total scale on the NM-EBPC, the ILS, and the ICS. The ILS and the ICS subscale and total scores were calculated separately for nurse managers and staff nurses, and independent t-tests with Bonferroni correction were used to test for significant differences between nurse manager and staff nurse scores. Significance was set at $\alpha<.05$.

\section{Results}

\section{Hospital and Unit Characteristics}

The sample included three small hospitals $\quad<100$ beds), two medium hospitals (100-300 beds), and two large hospitals (>300 beds). Units varied in bed size (range 9-45 beds) and primarily cared for older adult patients ( $>60$ years of age). Hospital and unit characteristics are further described in Table 1.

\section{Participants}

Response rates were $95.8 \%$ for nurse managers $(n=$ 23 ) and $51.9 \%$ for staff nurses $(n=287)$. Demographic characteristics of nurse managers and staff nurses are described in Table 2. The majority of nurse managers and staff nurses were Caucasian and female. Most nurse managers had a bachelor's $(52.2 \%)$ or master's degree $(30.4 \%)$, while the majority of staff nurses held a bachelor's $(59.2 \%)$ or associate's degree $(28.9 \%)$.

\section{Nurse Manager EBP Competencies}

The NM-EBPC (0-3 range) was completed by 22 nurse managers. In this study, the scale demonstrated high reliability for both subscales (Cronbach's $\alpha=.88$ for EBP Knowledge and $\mathrm{a}=.87$ for EBP Activity) and overall $(a=.93)$. Scale reliabilities and means and standard deviations for each item, subscale, and total scale are summarized in Table 3. The mean NM-EBPC total score was $1.62(S D=0.50)$. The mean EBP Knowledge subscale score $(1.77 ; S D=0.55)$ was slightly higher than the mean EBP Activity subscale score (1.53; $S D=0.49)$.

\section{Nurse Manager EBP Leadership Behaviors}

The ILS (0-4 range) was completed by 284 staff nurses and 23 nurse managers. In this study, the scale reliability was high among staff nurses (total, $\alpha=.97$; subscales, $\alpha=.89-.91)$ and among nurse managers $(\alpha=.84)$. The subscale reliability for nurse managers 
Table 3. Nurse Manager EBP Competency Scale: Reliabilities and Scores ( $N=22)$

\begin{tabular}{|c|c|c|c|c|}
\hline I am able to... & $\alpha$ & M & $S D$ & Rating 2-3 (\%) \\
\hline Subscale 1: EBP Knowledge & .88 & 1.77 & 0.55 & \\
\hline define EBP. & & 2.00 & 0.62 & 81.8 \\
\hline $\begin{array}{l}\text { locate primary evidence in bibliographic databases using search } \\
\text { terms. }\end{array}$ & & 1.68 & 0.78 & 59.1 \\
\hline $\begin{array}{l}\text { differentiate among primary evidence, systematic reviews, and } \\
\text { evidence-based guidelines. }\end{array}$ & & 1.41 & 0.67 & 40.9 \\
\hline $\begin{array}{l}\text { recognize ratings of strength of evidence when reading systematic } \\
\text { reviews and evidence summary reports. }\end{array}$ & & 1.27 & 0.83 & 40.9 \\
\hline $\begin{array}{l}\text { identify key criteria in well-developed evidence summary reports } \\
\text { using existing critical appraisal checklists. }\end{array}$ & & 1.41 & 0.59 & 45.5 \\
\hline $\begin{array}{l}\text { critically appraise original research reports for practical } \\
\text { implications. }\end{array}$ & & 1.32 & 0.72 & 36.4 \\
\hline Subscale 2: EBP Activity & .87 & 1.53 & 0.49 & \\
\hline $\begin{array}{l}\text { ensure that the delivery of care on my unit(s) aligns with EBP } \\
\text { recommendations. }\end{array}$ & & 1.82 & 0.73 & 63.6 \\
\hline evaluate processes and outcomes of EBP changes. & & 1.82 & 0.73 & 63.6 \\
\hline use evidence to inform clinical decision-making. & & 1.91 & 0.68 & 72.7 \\
\hline use criteria about EBP in screening and hiring staff. & & 1.09 & 0.87 & 31.8 \\
\hline $\begin{array}{l}\text { participate on a team to develop EBP recommendations for my } \\
\text { unit(s) and/or organization. }\end{array}$ & & 1.86 & 0.71 & 68.2 \\
\hline assist in implementing EBP changes in my unit(s) or organization. & & 2.00 & 0.62 & 81.8 \\
\hline participate in resolving issues related to implementing EBP. & & 1.77 & 0.69 & 63.6 \\
\hline $\begin{array}{l}\text { use audit and feedback of data as an implementation strategy for } \\
\text { EBP knowledge and use. }\end{array}$ & & 1.36 & 0.73 & 40.9 \\
\hline use criteria about EBP in performance evaluation of staff. & & 1.32 & 0.72 & 45.5 \\
\hline access clinical practice guidelines on various clinical topics. & & 1.86 & 0.64 & 72.7 \\
\hline Total scale & .93 & 1.62 & 0.50 & \\
\hline
\end{tabular}

Note. Scale range is 0 to $3(0$ = not competent; 1 = somewhat competent; 2 = fully competent; 3 = expertly competent $)$. EBP = evidence-based practice.

was low $(\alpha=.54)$ to acceptable $(\alpha=.70)$; see Table 4$)$. The mean total ILS score (0-4 range) for staff nurses was $2.88(S D=0.78)$ and for nurse managers was 2.73 $(S D=0.46)$. For the four subscales, Proactive Leadership had the lowest mean score among both staff nurses (2.67 $[S D=0.87])$ and nurse managers (2.25 [SD= $0.70])$, respondents tended to score nurse managers higher for Supportive Leadership (staff nurses: $M=3.03$ $[S D=0.80]$; nurse managers: $M=3.23[S D=0.54]$ ). Subscale scores of Proactive and Knowledgeable leadership were significantly different $(p<.05)$ for staff nurses and nurse managers, with staff nurses scoring nurse managers higher on average for both subscales than nurse managers scored themselves.

\section{Unit Climate for EBP Implementation}

Two hundred seventy-two staff nurses completed more than $50 \%$ of the ICS (0-4 range), while 22 nurse managers completed the ICS with no missing items. Reliability of the ICS was excellent in this study, with Cronbach's a of .94 and .92 among staff nurses and nurse managers, respectively. Subscale reliabilities were also good, with Cronbach's $\alpha$ of .72 or higher among both groups (see Table 5). The ICS total score (0-4 range) for staff nurses was $2.24(S D=0.74)$ and for nurse managers was $2.16(S D=0.67)$. The Focus subscale on EBP demonstrated the highest mean score of the staff nurse sample $(2.66[S D=0.85])$, whereas Hire for Openness was the highest scored subscale of the nurse manager sample $(M=2.72$ [ $S D=0.68])$. Both staff nurses and nurse managers scored Rewards for EBP the lowest (staff nurses: $M=1.4$ [SD =0.96]; nurse managers: $M=1.04[S D=0.99]$ ). No significant differences between staff nurses' and nurse managers' perceptions were observed.

\section{Discussion}

As one of the first examinations of nurse manager EBP competencies, nurse manager leadership behaviors supporting EBP, and unit climates for EBP implementation in acute care, this study shows these instruments perform well psychometrically and support their use in implementation research. The reliabilities of all three scales and most of their subscales were greater 
Table 4. Implementation Leadership Scale: Reliabilities and Scores by Role ( $n=284$ Staff RNs; $n=23$ Nurse Managers)

\begin{tabular}{|c|c|c|c|c|c|c|c|c|c|c|}
\hline \multirow[b]{3}{*}{$\begin{array}{l}\text { "I am/have..." (nurse manager version) "My nurse } \\
\text { manager is/has..." (staff RN version) }\end{array}$} & \multicolumn{2}{|c|}{ Reliability } & \multicolumn{6}{|c|}{ Mean score by role } & \multirow{2}{*}{\multicolumn{2}{|c|}{$\begin{array}{l}\text { RN compared } \\
\text { to NM }\end{array}$}} \\
\hline & \multirow{2}{*}{$\begin{array}{l}\mathrm{RN} \\
\alpha\end{array}$} & \multirow{2}{*}{$\frac{N M}{\alpha}$} & \multicolumn{3}{|l|}{$\mathrm{RN}$} & \multicolumn{3}{|l|}{ NM } & & \\
\hline & & & M & $S D$ & $\begin{array}{l}\text { Rating } \\
3-4(\%)\end{array}$ & M & $S D$ & $\begin{array}{l}\text { Rating } \\
3-4(\%)\end{array}$ & $t^{a}$ & $p^{b}$ \\
\hline \multirow{4}{*}{$\begin{array}{l}\text { Subscale 1: Proactive Leadership } \\
\text { established clear standards for implementation of } \\
\text { EBP. } \\
\text { developed a plan to facilitate EBP implementation. } \\
\text { removed obstacles to implementation of EBP. }\end{array}$} & \multirow[t]{4}{*}{.90} & \multirow[t]{4}{*}{.65} & 2.67 & 0.87 & & 2.25 & 0.70 & & \multirow[t]{4}{*}{2.75} & \multirow[t]{4}{*}{.01} \\
\hline & & & 2.80 & 0.91 & 64.8 & 2.22 & 1.13 & 39.1 & & \\
\hline & & & 2.68 & 0.97 & 59.5 & 2.22 & 0.85 & 30.4 & & \\
\hline & & & 2.54 & 0.95 & 53.5 & 2.30 & 0.70 & 43.5 & & \\
\hline Subscale 2: Knowledgeable Leadership & \multirow[t]{4}{*}{.91} & \multirow[t]{4}{*}{.70} & 2.99 & 0.80 & & 2.54 & 0.53 & & \multirow[t]{4}{*}{3.80} & \multirow[t]{4}{*}{$<.001$} \\
\hline $\begin{array}{l}\text { knows what he/she is talking about when it comes to } \\
\text { EBP. }\end{array}$ & & & 2.98 & 0.91 & 74.6 & 2.48 & 0.67 & 60.9 & & \\
\hline is knowledgeable about EBP. & & & 3.12 & 0.77 & 81.3 & 2.74 & 0.62 & 65.2 & & \\
\hline is able to answer staff questions about EBP. & & & 2.89 & 0.92 & 72.9 & 2.39 & 0.72 & 43.5 & & \\
\hline Subscale 3: Supportive Leadership & \multirow[t]{4}{*}{.89} & \multirow[t]{4}{*}{.54} & 3.03 & 0.80 & & 3.23 & 0.54 & & \multirow[t]{4}{*}{-1.66} & \multirow[t]{4}{*}{.11} \\
\hline $\begin{array}{l}\text { recognizes and appreciates employee efforts toward } \\
\text { successful implementation of EBP. }\end{array}$ & & & 3.02 & 0.85 & 77.5 & 2.83 & 0.98 & 73.9 & & \\
\hline supports employee efforts to learn more about EBP. & & & 2.98 & 0.95 & 72.9 & 3.48 & 0.51 & 100 & & \\
\hline supports employee efforts to use EBP. & & & 3.09 & 0.86 & 79.6 & 3.39 & 0.66 & 91.3 & & \\
\hline \multirow{2}{*}{$\begin{array}{l}\text { Subscale 4: Perseverant Leadership } \\
\text { reacts to critical issues regarding the implementation } \\
\text { of EBP by openly and effectively addressing the } \\
\text { problem(s). }\end{array}$} & \multirow[t]{4}{*}{.91} & \multirow[t]{4}{*}{.57} & 2.84 & 0.84 & & 2.88 & 0.50 & & \multirow[t]{4}{*}{-0.39} & \multirow[t]{4}{*}{.70} \\
\hline & & & 2.88 & 0.91 & 70.4 & 3.00 & 0.80 & 78.3 & & \\
\hline $\begin{array}{l}\text { carries on through the challenges of implementing } \\
\text { EBP. }\end{array}$ & & & 2.83 & 0.90 & 69.7 & 2.87 & 0.63 & 73.9 & & \\
\hline $\begin{array}{l}\text { perseveres through the ups and downs of implement- } \\
\text { ing EBP. }\end{array}$ & & & 2.81 & 0.93 & 67.3 & 2.78 & 0.60 & 69.6 & & \\
\hline Total scale & .97 & .84 & 2.88 & 0.78 & & 2.73 & 0.46 & & 1.49 & .15 \\
\hline
\end{tabular}

Note. Scale range is 0 to 4 ( 0 = not at all;; 1 = slight extent; 2 = moderate extent; 3 = great extent; 4 = very great extent). EBP = evidence-based practice; NM = nurse manager; $\mathrm{RN}$ = registered nurse.

andependent $t$-test.

${ }^{\mathrm{b} B o n f e r r o n i}$ corrected.

than .70. Three of the four ILS subscales did not demonstrate acceptable reliability among nurse managers, including subscales for Proactive, Supportive, and Perseverant leadership, which may be due to the small sample size of nurse managers $(n=23)$. Future research should further test the reliability of the ILS subscales among nurse managers using a larger sample.

The results identify significant opportunities for improvements in the EBP competencies and leadership behaviors of nurse managers. Nurse managers perceived that they were somewhat but not fully competent in EBP knowledge and activities as total scores were less than 2 (fully competent) on average. Although some competency items, notably "able to define EBP," "able to use evidence to inform clinical decision making," "able to assist in implementing EBP changes," and "able to access clinical practice guidelines on various clinical topics," were scored positively by most respondents, significant deficiencies (less than 50\% of sample rating the item as "fully competent" or "expertly competent") were observed in almost half of the competencies. Managerial competencies recognized by professional groups, such as the American Organization of Nurse Executives (2015), should include EBP competencies and leadership. Improving nurse managerial EBP competency may likely contribute to improved EBP leadership and unit implementation efforts, which ultimately improves patient care and outcomes.

Most nurse manager leadership behaviors were reported as moderate, with proactive leadership behaviors receiving the lowest scores by both staff nurses and nurse managers. Only $30 \%$ to $43.5 \%$ of nurse managers rated items in this domain positively ("great extent" or "very great extent"). This is concerning because leadership support is critical for promoting 
Table 5. Implementation Climate Scale: Reliabilities and Scores by Role ( $\boldsymbol{n}=272$ Staff RNs; $\boldsymbol{n}=22$ Nurse Managers)

\begin{tabular}{|c|c|c|c|c|c|c|c|c|c|c|}
\hline & \multicolumn{2}{|c|}{ Reliability } & \multicolumn{6}{|c|}{ Score by role } & \multirow{2}{*}{\multicolumn{2}{|c|}{$\begin{array}{l}\text { RN compared to } \\
\text { NM }\end{array}$}} \\
\hline & \multirow{2}{*}{$\frac{\mathrm{RN}}{\alpha}$} & \multirow{2}{*}{$\frac{N M}{\alpha}$} & \multicolumn{3}{|l|}{ RN } & \multicolumn{3}{|l|}{ NM } & & \\
\hline & & & M & $S D$ & Rating 3-4 (\%) & M & SD & Rating 3-4 (\%) & $t^{a}$ & $p^{b}$ \\
\hline Subscale 1: Focus on EBP & .89 & .83 & 2.66 & 0.85 & & 2.67 & 0.80 & & -0.03 & .97 \\
\hline $\begin{array}{l}\text { Using EBPs is a top priority } \\
\text { in my unit. }\end{array}$ & & & 2.66 & 0.97 & 59.9 & 2.78 & 0.80 & 56.5 & & \\
\hline $\begin{array}{l}\text { People in my unit think that } \\
\text { the implementation of } \\
\text { EBP is important. }\end{array}$ & & & 2.64 & 0.87 & 61.8 & 2.70 & 0.93 & 65.2 & & \\
\hline $\begin{array}{l}\text { One of my unit's main goals } \\
\text { is to use EBP effectively. }\end{array}$ & & & 2.68 & 0.97 & 60.3 & 2.52 & 1.04 & 47.8 & & \\
\hline $\begin{array}{l}\text { Subscale 2: Educational } \\
\text { Support for EBP }\end{array}$ & .82 & .75 & 2.26 & 0.93 & & 2.23 & 0.89 & & 0.16 & .87 \\
\hline $\begin{array}{l}\text { My unit provides EBP } \\
\text { trainings or in-services. }\end{array}$ & & & 2.28 & 1.02 & 40.1 & 2.00 & 1.35 & 39.1 & & \\
\hline $\begin{array}{l}\text { My unit provides opportuni- } \\
\text { ties to attend confer- } \\
\text { ences, workshops, or } \\
\text { seminars focusing on } \\
\text { EBP. }\end{array}$ & & & 2.38 & 1.14 & 48.5 & 2.43 & 0.95 & 47.8 & & \\
\hline $\begin{array}{l}\text { My unit provides EBP } \\
\text { training materials, } \\
\text { journals, etc. }\end{array}$ & & & 2.14 & 1.08 & 37.1 & 2.26 & 0.92 & 39.1 & & \\
\hline $\begin{array}{l}\text { Subscale 3: Recognition for } \\
\text { EBP }\end{array}$ & .77 & .75 & 2.38 & 0.83 & & 2.25 & 0.82 & & 0.75 & .46 \\
\hline $\begin{array}{l}\text { Clinicians who use EBPs are } \\
\text { held in high esteem in my } \\
\text { unit. }\end{array}$ & & & 2.77 & 0.86 & 65.4 & 2.48 & 0.95 & 52.2 & & \\
\hline $\begin{array}{l}\text { Clinicians in my unit who } \\
\text { use EBPs are seen as } \\
\text { clinical experts. }\end{array}$ & & & 2.51 & 0.98 & 53.3 & 2.61 & 1.03 & 65.2 & & \\
\hline $\begin{array}{l}\text { Clinicians in my unit who } \\
\text { use EBPs are more likely } \\
\text { to be promoted. }\end{array}$ & & & 1.86 & 1.17 & 30.1 & 1.65 & 1.03 & 26.1 & & \\
\hline Subscale 4: Rewards for EBP & .73 & .72 & 1.40 & 0.96 & & 1.04 & 0.99 & & 1.69 & .10 \\
\hline $\begin{array}{l}\text { My unit provides the ability } \\
\text { to accumulate compen- } \\
\text { sated time for the use of } \\
\text { EBPs. }\end{array}$ & & & 1.86 & 1.18 & 29.8 & 1.39 & 1.20 & 17.4 & & \\
\hline $\begin{array}{l}\text { My unit provides financial } \\
\text { incentives for the use of } \\
\text { EBPs. }\end{array}$ & & & 1.06 & 1.21 & 14.0 & 0.91 & 1.47 & 21.7 & & \\
\hline $\begin{array}{l}\text { The better you are at using } \\
\text { EBPs, the more likely you } \\
\text { are to get a raise. }\end{array}$ & & & 1.31 & 1.17 & 16.5 & 0.83 & 0.98 & 8.7 & & \\
\hline Subscale 5: Selection for EBP & .87 & .84 & 2.25 & 0.94 & & 2.03 & 0.85 & & 1.17 & .25 \\
\hline $\begin{array}{l}\text { My unit hires staff who } \\
\text { value EBP. }\end{array}$ & & & 2.35 & 1.01 & 46.0 & 2.30 & 0.97 & 43.5 & & \\
\hline $\begin{array}{l}\text { My unit hires staff who have } \\
\text { had formal education } \\
\text { supporting EBP. }\end{array}$ & & & 2.19 & 1.14 & 42.6 & 1.91 & 0.95 & 26.1 & & \\
\hline $\begin{array}{l}\text { My unit hires staff who have } \\
\text { previously used EBPs. }\end{array}$ & & & 2.19 & 0.99 & 39.3 & 1.87 & 1.01 & 34.8 & & \\
\hline $\begin{array}{l}\text { Subscale 6: Selection for } \\
\text { Openness }\end{array}$ & .87 & .87 & 2.49 & 0.80 & & 2.72 & 0.68 & & -1.59 & $\begin{array}{l}.12 \\
\text { (Continues) }\end{array}$ \\
\hline
\end{tabular}


Table 5. (Continued)

\begin{tabular}{|c|c|c|c|c|c|c|c|c|c|c|}
\hline & \multicolumn{2}{|c|}{ Reliability } & \multicolumn{6}{|c|}{ Score by role } & \multirow{2}{*}{\multicolumn{2}{|c|}{$\begin{array}{l}\text { RN compared to } \\
\text { NM }\end{array}$}} \\
\hline & \multirow{2}{*}{$\frac{\mathrm{RN}}{\alpha}$} & \multirow{2}{*}{$\frac{N M}{\alpha}$} & \multicolumn{3}{|l|}{ RN } & \multicolumn{3}{|l|}{ NM } & & \\
\hline & & & M & $S D$ & Rating 3-4 (\%) & M & $S D$ & Rating 3-4 (\%) & $t^{a}$ & $p^{\mathrm{b}}$ \\
\hline $\begin{array}{l}\text { My unit hires staff who are } \\
\text { flexible. }\end{array}$ & & & 2.51 & 0.89 & 50.7 & 2.91 & 0.67 & 82.6 & & \\
\hline $\begin{array}{l}\text { My unit hires staff who are } \\
\text { adaptable. }\end{array}$ & & & 2.58 & 0.86 & 55.9 & 2.78 & 0.85 & 69.6 & & \\
\hline $\begin{array}{l}\text { My unit hires staff open to } \\
\text { new types of } \\
\text { interventions. }\end{array}$ & & & 2.37 & 0.92 & 46.7 & 2.48 & 0.90 & 52.2 & & \\
\hline Total scale & .94 & .92 & 2.24 & 0.74 & & 2.16 & 0.67 & & 0.57 & .58 \\
\hline
\end{tabular}

Note. Scale range is 0 to $4(0=$ not at all; 1 = slight extent; 2 = moderate extent; 3 = great extent; 4 = very great extent $)$. EBP = evidence-based practice; NM = nurse manager; $\mathrm{RN}$ = registered nurse.

andependent t-test.

bonferroni corrected.

use of EBPs and is expressed verbally, and by providing necessary resources, materials, and time to fulfill responsibilities (Everett 8 Sitterding, 2011; French et al., 2009; Sandström et al., 2011; Stetler, Ritchie, RycroftMalone, Schultz, \& Charns, 2009). Numerous administrative responsibilities may deter nurse managers from proactive behaviors, such as establishing unit standards for EBP or developing a plan for EBP implementation (Wilkinson, Nutley, \& Davies, 2011). Interestingly, staff nurses perceived their managers to be more proactive and knowledgeable regarding EBP than managers perceived themselves. Aarons, Ehrhart, Torres, Finn, \& Beidas (2017) observed similar divergent perspectives and contend that some leaders rate themselves lower out of humility. Furthermore, staff consider nurse managers to be clinical and managerial experts (knowledgeable leadership) who maintain and evaluate unit standards (proactive leadership; Baxter \& Warshawsky, 2014; Duffield, Roche, Blay, \& Stasa, 2011).

Implementation climate total scores suggest that the practice climates for implementation of EBPs are less than optimal. Subscale scores indicate that practice climates rewarding EBP are relatively unsupported and that the units had climates only moderately prepared with EBP educational support, hiring staff who value EBP, and recognizing staff for EBP. This is concerning because rewards, provision of educational support, and selection of new staff are all key indicators of whether practice climates are conducive to EBP implementation (Aarons, Ehrhart, Farahnak, \& Sklar, 2014). Since nurse managers are instrumental in creating and maintaining unit climates supportive of EBP implementation, development and testing of an intervention targeting nurse managers' competencies, leadership behaviors, and creation of practice climates for implementation of EBPs is warranted.

\section{Implications for Clinical Practice}

Findings from this study have relevance for practice. First, when planning for implementation of an EBP in a specific practice setting, consideration should be given to assessing the nurse manager leadership behaviors and implementation climate. The results from the assessment can guide selection of implementation strategies that may otherwise be overlooked. For example, if scores for recognition and reward from the ICS are low to moderate, the implementation plan should include how staff will be recognized and rewarded for their work in implementing the EBP. Recognition can be achieved through organizational publications such as newsletters, personal thank you notes from the nurse manager, highlighting the work at system level quality improvement meetings, and nominating individuals or teams for practice excellence awards offered by the health system or professional organizations. Rewards may be offered to an individual or team who has been instrumental in implementing the EBP through receipt of financial support to attend a regional or national conference to present their work.

Second, findings suggest that these three key context factors that impact implementation should be routinely assessed to build strong organizational capacity for adoption of EBPs. Results of the assessment should be examined for opportunities to strengthen organizational capacity for EBP and guide organizational interventions and programs to address these areas of opportunity. For example, if scores for hiring staff that value EBP are low (as rated by the majority of this study's sample), an organization may want to examine hiring practices and interview questions 
used in selection of staff. Additionally, considerable work is needed to improve staff perceptions of rewards allocated for EBP use by staff. This may be accomplished by including EBP criteria in staff evaluations (an EBP competency of nurse managers) for promotion and raises (markers of a strong EBP climate).

Third, because nurse managers of practice sites (e.g., ambulatory care clinic, patient care unit) where EBPs will be implemented are key to success (Birken et al., 2016; Wilkinson et al., 2011), organizations should provide didactic and experiential learning for nurse managers to achieve EBP competencies and leadership for EBP. Training should be targeted to areas requiring improvement. Future research is needed to develop these training programs.

\section{Limitations}

This study has some limitations. A convenience sample of hospitals was used for the study, which may affect generalizability, although different-sized hospitals with varied characteristics were recruited from diverse regions to minimize this limitation. Also, since only adult medicalsurgical units were included, the results from this study may have limited generalizability to other types of nursing units (e.g., intensive care, pediatric, ambulatory care, long-term care). We recognize the importance of replicating this study in other types of patient care units and settings. Although the ILS total score reliability among nurse managers was good, subscale reliabilities were low and should be interpreted cautiously.

\section{Conclusions}

The results of this study provide evidence supporting the reliability of using these scales in hospital settings with staff nurses and nurse managers. EBP leadership behaviors and competencies of nurse managers and climates supportive of EBP in hospital settings were modest at best. Therefore, investigators studying implementation should incorporate these three dynamic context factors into their research. We are unlikely to close the critical gap between research and practice if studies do not examine the interplay between dynamic context factors and the implementation strategies used to promote uptake of EBPs. For practice, critical attention is needed to build organizational capacity for EBPs through development of unit leadership and climates for EBP to accelerate routine use of EBPs for improving care delivery and patient outcomes.

\section{Clinical Resources}

- American Organization of Nurse Executives. http://www.aone.org/

- National Nursing Practice Network. http://www. nnpnetwork.org/

\section{References}

Aarons, G. A., Ehrhart, M. G., \& Farahnak, L. R. (2014). The implementation leadership scale (ILS): Development of a brief measure of unit level implementation leadership. Implementation Science, 9, Article 45.

Aarons, G. A., Ehrhart, M. G., Farahnak, L. R., \& Sklar, M. (2014). Aligning leadership across systems and organizations to develop a strategic climate for evidence-based practice implementation. Annual Review of Public Health, 35, 255-274.

Aarons, G. A., Ehrhart, M. G., Torres, E. M., Finn, N. K., \& Beidas, R. S. (2016). The humble leader: Association of discrepancies in leader and follower ratings of implementation leadership with organizational climate in mental health. Psychiatric Services, 68(2), 115-122.

American Organization of Nurse Executives. (2015). AONE nurse manager competencies. Chicago, IL: Author.

Baxter, C., \& Warshawsky, N. (2014). Exploring the acquisition of nurse manager competence. Nurse Leader, 12(1), 46-51.

Birken, S. A., DiMartino, L. D., Kirk, M. A., Lee, S. Y. D., McClelland, M., \& Albert, N. M. (2016). Elaborating on theory with middle managers' experience implementing healthcare innovations in practice. Implementation Science, 11, Article 2.

Damschroder, L. J., Aron, D. C., Keith, R. E., Kirsh, S. R., Alexander, J. A., \& Lowery, J. C. (2009). Fostering implementation of health services research findings into practice: A consolidated framework for advancing implementation science. Implementation Science, 4, Article 50.

Duffield, C. M., Roche, M. A., Blay, N., \& Stasa, H. (2011). Nursing unit managers, staff retention and the work environment. Journal of Clinical Nursing, 20(1-2), 23-33.

Ehrhart, M. G., Aarons, G. A., \& Farahnak, L. R. (2014). Assessing the organizational context for EBP implementation: The development and validity testing of the Implementation Climate Scale (ICS). Implementation Science, 9, Article 157. 
Ehrhart, M. G., Schneider, B., \& Macey, W. H. (2014). Organizational climate and culture: An introduction to theory, research, and practice. New York, NY: Routledge.

Everett, L. Q., \& Sitterding, M. C. (2011). Transformational leadership required to design and sustain evidence-based practice: A system exemplar. Western Journal of Nursing Research, 33(3), 398-426.

French, B., Thomas, L. H., Baker, P., Burton, C. R., Pennington, L., \& Roddam, H. (2009). What can management theories offer evidence-based practice? A comparative analysis of measurement tools for organisational context. Implementation Science, 4, Article 28.

Gifford, W., Davies, B., Edwards, N., Griffin, P., \& Lybanon, V. (2007). Managerial leadership for nurses' use of research evidence: An integrative review of the literature. Worldviews on Evidence-Based Nursing, 4(3), 126-145.

Kitson, A., Harvey, G., \& McCormack, B. (1998). Enabling the implementation of evidence based practice: A conceptual framework. Quality in Health Care, 7(3), 149-158.

Kitson, A. L., \& Harvey, G. (2016). Methods to succeed in effective knowledge translation in clinical practice. Journal of Nursing Scholarship, 48(3), 294-302.

Kitson, A. L., Rycroft-Malone, J., Harvey, G., McCormack, B., Seers, K., \& Titchen, A. (2008). Evaluating the successful implementation of evidence into practice using the PARiHS framework: Theoretical and practical challenges. Implementation Science, 3, Article 1.

May, C. R., Johnson, M., \& Finch, T. (2016). Implementation, context and complexity. Implementation Science, 11, Article 141.

Qualtrics Software. (2015). Version 60816 of the Qualtrics Research Suite. Copyright (C) 2015 Qualtrics. Retrieved from http://www.qualtrics.com

$\mathrm{R}$ Core Team. (2016). R: A language and environment for statistical computing. Vienna, Austria: R Foundation for Statistical Computing. Retrieved from https://www.R-project.org/

Sandström, B., Borglin, G., Nilsson, R., \& Willman, A. (2011). Promoting the implementation of evidence-based practice: A literature review focusing on the role of nursing leadership. Worldviews on Evidence-Based Nursing, 8(4), 212-223.

Schein, E. (2010). Organizational culture and leadership (5th ed.). Hoboken, NJ: Wiley \& Sons.

Schneider, B., Ehrhart, M. G., \& Macey, W. H. (2013). Organizational climate and culture. Annual Review of Psychology, 64, 361-388.

Shuman, C. (2017). Addressing the practice context in evidence-based practice implementation: Leadership and climate (Doctoral dissertation). Retrieved from Deep Blue website: http://hdl.handle. net/2027.42/138458

Shuman, C., Ploutz-Snyder, R., \& Titler, M. (2018). Development and testing of the Nurse Manager EBP Competency Scale. Western Journal of Nursing Research, 40(2), 175-190.

Shuman, C. J., Liu, X., Aebersold, M. L., Tschannen, D., Banaszak-Holl, J., \& Titler, M. G. (2018). Associations among unit leadership and unit climates for implementation in acute care: A cross-sectional study. Implementation Science, 13, Article 62.

Stetler, C. B., Ritchie, J. A., Rycroft-Malone, J., Schultz, A. A., \& Charns, M. P. (2009). Institutionalizing evidence-based practice: An organizational case study using a model of strategic change. Implementation Science, 4, Article 78.

Titler, M. G. (2010). Translation science and context. Research and Theory for Nursing Practice, 24(1), 35-55.

Wilkinson, J. E., Nutley, S. M., \& Davies, H. T. (2011). An exploration of the roles of nurse managers in evidence-based practice implementation. Worldviews on Evidence-Based Nursing, 8(4), 236-246.

\section{Supporting Information}

Additional supporting information may be found in the online version of this article at the publisher's web site:

Figure S1. Conceptual model.

Figure S2. Data collection timeline. 